УДК 622.831

\title{
ПРИРОДНО-ТЕХНОГЕННЫЕ КАТАСТРОФЫ КАК ПРОЯВЛЕНИЯ ГЕОДИНАМИЧЕСКОЙ НЕСТАБИЛЬНОСТИ ЗЕМНОЙ КОРЫ
}

\author{
Борисов Константин Иванович',
} kibor1956@gmail.com

Горшков Лев Капитонович², maneb@mail.ru

\author{
Софьин Алексей Петрович², \\ as-114@yandex.ru \\ Федорова Людмила Анатольевна², \\ kingalya@mail.ru \\ Сибирский федеральный университет, \\ Россия, 660041, г. Красноярск, пр. Свободный, 79/10. \\ 2 Международная академия наук экологии, безопасности человека и природы, \\ Россия, 199026, г. Санкт-Петербург, 26 линия Васильевского острова, 9.
}

\begin{abstract}
Актуальность. Геодинамическая нестабильность - причина многих природных катастроф: землетрясений, извержений вулканов, оползней, цунами. Природные катастрофы могут инициировать техногенные аварии (обрушения зданий и сооружений, взрывы на шахтах, нарушения целостности плотин и др.) и, наоборот, техногенные процессы могут вызывать появление новых природных объектов, например, с ними связано создание искусственных водохранилищ. Широко распространенная в мире добыча нефти и газа может провоцировать подвижки в земной коре с трагическими последствиями. Особенности условий для активизации геодинамической нестабильности определяют уровень безопасности персонала технических объектов и качество эксплуатации сооружений, систем и агрегатов. Случайный характер процессов в земной коре в значительной мере формирует возможность прогнозирования техногенных катастроф и проведения мероприятий для парирования негативных факторов, связанных, в том числе, с безопасностью персонала и населения. Рекомендации по предупреждению и прогнозу природно-техногенных катастроф и условия их возникновения основаны на сопоставлении различных точек зрения на активизацию геодинамической нестабильности Земли, а также выявлении степени влияния на нее сезонной периодичности характерных процессов. Обоснован уровень значимости параметров движения Земли в формировании условий активизации геодинамической нестабильности. Однако, современное состояние вопроса диктует необходимость дополнительных исследований в данной области, что частично восполняет данная статья.
\end{abstract}

Цель: определить и предложить вариант подхода к анализу условий возникновения катастрофической ситуации.

Объекты: геодинамические процессы в земной коре и варианты комбинаций условий для их возникновения.

Методы: обзор и анализ существующей научно-технической информации по проблеме геодинамической стабильности земной коры и постановка задач исследований.

Результаты. Выявлены и обоснованы причины возникновения аварийных ситуаций, связанных с геодинамическими процессами в земной коре.

\section{Ключевые слова:}

Геодинамическая нестабильность, земная кора, экзогенные и эндогенные процессы, пульсационная гипотеза, природно-техногенные катастрофы, техногенные аварии, импульс силы, период, закон И. Кеплера, ротационно-импульсный режим.

\section{Введение}

Вопросы размещения и успешной эксплуатации объектов наземной инфраструктуры неразрывно связаны с устойчивостью зданий и сооружений в зонах земной коры с высокой вероятностью природных и техногенных катастроф. Анализ основных причин возникновения условий разрушения или повреждения технических, стартовых и иных сооружений показал необходимость исследования процессов в земной коре, имеющих, чаще всего, выраженную географическую привязку и сезонный характер. Вопросам исследования причин возникновения природных и антропогенных катастроф посвящены труды многих ученых [1-5], в которых показано, что видимые и поддающиеся изучению природные и техногенные катастрофы случаются в земной коре благодаря сложному взаимодействию внутренних (эндогенных) и поверхностных или приповерхностных (экзогенных) процессов. Причем первые процессы создают крупные неровности рельефа тектонического и вулканического происхождения, а вторые стремятся сгладить их путем разрушения выступов на поверхности (денудация) или заполнения понижений осадками (аккумуляция).

Геодинамика как наука о глубинных силах и процессах [6, 7], определяющих движение масс вещества и энергии внутри Земли и в ее внешних оболочках (в первую очередь, в литосфере и гидросфере), исследует сокращение, расширение или 
попеременное изменение радиуса Земли, что является основой пульсационной гипотезы академика В.А. Обручева и американского геолога У. Бачера.

Многократные колебания объема Земли (пульсации) являются причинами периодического возрастания деформаций сжатия и расширения как самой земной коры, так и подвижных ее зон, усиления вулканизма, возникновения трансгрессий и регрессий мирового уровня, следствиями которых становятся природные катастрофы: землетрясения различных интенсивностей и масштабов, вулканические извержения, перемещения и изменения внутренней структуры участков или блоков земной коры (тектонические нарушения), а также метаморфические процессы под влиянием повышенных температур и давлений [8].

Все перечисленные процессы и определяют геодинамическую нестабильность и ее связь с природно-техногенными катастрофами. При этом природные катастрофы нередко перемежаются с техногенными. Последние довольно часто могут выступить в роли пусковых толчков для природных, а сами природные катастрофы (например, связанные с пульсационными процессами) могут провоцировать и дополнять техногенные катастрофы. Конечно, природные катастрофы типа землетрясений, извержений вулканов, оползней, селей невозможно не только предсказать, но и тем более предотвратить. Нельзя при этом не отметить и тот факт, что часто роль природных факторов игнорируется при анализе техногенных катастроф, например, в горнодобывающей промышленности, в энергетике, при строительстве протяженных нефте- и газопроводов и т.п.

Пульсации объема земной коры вызывают геодинамическую нестабильность, согласно выводам M.В. Стоваса [9], главным образом, в широтных поясах вследствие колебаний величины скорости движения Земли по плоской эллиптической орбите вокруг Солнца в резонансе с прецессией земной оси. Одним из таких поясов геодинамической нестабильности можно назвать полосу $51-54^{\circ}$ с.ш., в которой сравнительно недавно имели место трагические события $[10,11]$, например: гидроразрыв сети водоснабжения в г. Саратове $\left(46^{\circ}\right.$ в.д.); авария на Саяно-Шушенской ГЭС (92 в.д.); активизация вулканов Шивелуча, Ключевского и Карымского на Камчатке (около $161^{\circ}$ в.д.). Геодинамически нестабильные пояса возникают, в соответствии с высказанной выше гипотезой того же М.В. Стоваса, из-за изменений потенциала деформирующих земную кору сил. Кроме того, нестабильность может быть инициирована и солнечным излучением, аномалиями гравитации, магнитных и электромагнитных процессов, акустической эмиссией и т.п.

\section{Влияние природных условий}

На особенности развития геодинамических процессов накладывается широкий спектр природных условий нашей страны [11, 12]. Природная геодинамическая нестабильность земной коры мо- жет проявляться не только в виде катастрофических землетрясений и им подобных процессов, но и как «спокойная» природная саморегуляция напряженного состояния: подвижки пластичных пород, неявные до определенного уровня; вертикальные смещения блоков с заполнением образовавшихся пустот водотоками, а также тектонические оперения крупных разломов и сдвигов. Эти, на первый взгляд, незаметные явления могут спровоцировать и техногенные аварии, и даже катастрофы: гидроудар в Саратове мог быть вызван микросбросом в несущем блоке горных пород; технические просчеты при проектировании Саяно-Шушенской ГЭС с высокой долей вероятности могли быть усилены «спокойным» пластическим смещением пород фундаментов, опор, отдельных блоков ГЭС; дискуссируемый в средствах массовой информации и в научной литературе поворот сибирских рек на юг способен вызвать дисбаланс количества движения планеты из-за усиления ее анизотропности.

Список произошедших, а также возможных в будущем аварий и катастроф по причине естественной и наведенной (техногенной) геодинамической нестабильности можно продолжать и далее, но вывод из всего сказанного очевиден: необходимо учитывать естественную и наведенную напряженность в земной коре при строительстве крупных наземных, подземных, акваториальных и подводных объектов, а также изменение этой напряженности при сооружении подземных газо- и водохранилищ, плотин, дамб, атомных станций, хранилищ ядерных отходов и др., с тем, чтобы обеспечить их безопасную, для людей и природы, эксплуатацию, эффективные безаварийные технологии, отталкиваясь от природных факторов. Сравнение уровней естественной напряженности в земной коре, соответствующей проявлениям глобальной геодинамической нестабильности, например, с давлением в глубоких геотермальных скважинах или, особенно, в скважинах на нефтегазовых промыслах, свидетельствует о близком порядке их количественных значений. Все сказанное подтверждает настоятельную необходимость прогнозировать последствия от быстро расширяющейся в своих масштабах утилизации глубинных энергоносителей (нефти, газа, парогидротерм) как негативного воздействия на геодинамический режим земной коры.

О причинах пульсаций объема Земли как нестабильной геодинамической системы существует достаточно много мнений, суть некоторых из них рассмотрим ниже, хотя об одной (гипотезе М.В. Стоваса) уже говорилось. Астроном Н.Н. Парийский полагал [13], что пульсация объема Земли вызывается изменениями ее средней температуры, зависящей от разности расстояний между Землей и Солнцем в перигелии и афелии. Так, по его расчетам, при разности средних температур Земли в марте и августе в $1,4{ }^{\circ} \mathrm{C}$ изменение радиуса Земли составляет 0,092 м, что представляется несуществен- 
ным по сравнению с размерами не только самой Земли, но даже и с толщиной земной коры.

По мнению академика В.А. Амбарцумяна [14], причиной пульсаций объема Земли является ее периодическое переуплотнение из-за разности напряженностей гравитационного и электромагнитного полей, в пределах которых совершается движение всех космических тел. Эта гипотеза достаточно реалистична, имеет право на существование, но не снимает трудностей при ее практическом использовании для прогноза земных катастроф и их предупреждения. Пульсационная теория изменения объема Земли получила широкое распространение $[15,16]$.

Кроме того, есть точка зрения, приведенная в работе [6], объясняющая пульсации объема Земли как планеты фазовыми переходами слагающего ее вещества в процессе эволюции. Но эволюция процесс, насчитывающий миллиарды лет, поэтому представляется проблематичным использование ее законов для решения практических задач в настоящее, конкретное время. Более того, до сих пор не ясно внутреннее строение самой планеты, как и механизм фазовых переходов веществ, образующих внутреннюю структуру Земли.

Таким образом, независимо от природы пульсаций объема Земли реальность этой пульсации доказана, как полагает тектонист Е.Е. Милановский [17], и это нужно учитывать и использовать на практике. Наряду с пульсацией необходимо отметить еще один режим, определяющий геодинамическую нестабильность Земли, - ротационный режим ее движения, реальность которого подтверждена в середине прошлого века одновременно тремя службами времени: Парижской (1934-1947), Гринвичской (1933-1949) и Берлинской (1938-1945).

Хотя термин «ротационный режим» ввел в механику не Иоганн Кеплер, но именно он дал первые объяснения по этому поводу в своих законах: в первом законе Кеплер показал, что Земля и другие планеты солнечной системы движутся не по круговым (как предполагал Н. Коперник), а по эллиптическим орбитам; согласно второму закону, при движении планет по эллиптическим орбитам радиусы-векторы планет за равные промежутки времени описывают равноплощадные сектора; третий закон, хотя и не имеет такого значения, как два первых закона, позволяет определить некоторые характеристики небесных тел, например, их массы, принимая массу Солнца за единицу.

Сущность ротационного движения Земли объясняется законом сохранения ее количества движения. Сила притяжения Земли к Солнцу является, согласно определению, приводимому в курсе теоретической механики, центральной силой, то есть силой, линия действия которой всегда проходит через определенный центр, в нашем случае, через фокус эллиптической орбиты Земли, в котором находится Солнце. Это значит, что момент этой центральной силы относительно фокуса (Солнца) равен нулю, и тогда вектор момента коли- чества движения Земли относительно названного фокуса $\left(\vec{K}_{S}\right)$ является постоянной величиной.

Модуль этого вектора является постоянной величиной и равен скалярному произведению

$$
K_{S}=m v h \text {, }
$$

где $m$ - масса Земли; $v$ - ее линейная скорость; $h$ расстояние от Земли до Солнца, меняющееся от минимума в перигелии до максимума в афелии (рис. 1).

Постоянство модуля вектора момента количества движения Земли относительно названного фокуса $\left(\vec{K}_{S}\right)$ обеспечивается изменением скорости $v$ при изменении величины $h$. Таким образом, радиус-вектор $\vec{r}$ Земли по отношению к Солнцу описывает за определенное время равные сектора (заштрихованные площадки на рисунке, где $r_{1} \leq r \leq r_{2}$ ), что определяет закон площадей, частным случаем которого является второй закон Кеплера:

$$
v_{1} h_{1}=v_{2} h_{2},
$$

где $h_{1}=S M_{1} ; h_{2}=S M_{2}$ (рис. 1$)$.

Практически это означает, что вблизи Солнца (в перигелии) Земля движется быстрее, чем в афелии. Чтобы обеспечить этот эффект, рост скорости движения Земли в перигелии должен компенсироваться уменьшением угловой скорости её вращения. Такого же рода компенсация должна иметь место и в афелии, но с обратным знаком.

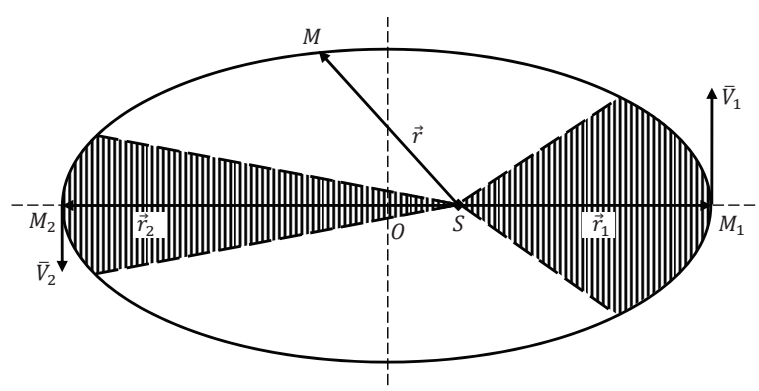

Pис. 1. Схема, поясняющая второй закон И. Кеплера (заштрихованные участки имеют равные площади)

Fig. 1. Scheme explaining the second law of I. Kepler (shaded regions have equal area)

Снижение скорости движения планеты по орбите восполняется увеличением угловой скорости вращения. В этом и заключается суть ротационного движения Земли, также оказывающего свое влияние на изменение объема планеты.

\section{Проявления геодинамической нестабильности}

Беглый анализ временных границ проявления техногенных катастроф и крупных аварий показывает [17-32], что чаще всего они приурочиваются к периоду между серединой августа одного года и серединой-концом марта следующего года, то есть примерно семь месяцев, о чем уже говорилось в связи с определением средних температур Земли в марте и августе. $К$ этому же периоду приурочиваются и крупные природные катастрофы: в течение названных семи месяцев в XX в. происходило в 
разные годы более трех четвертей крупных и масштабных по разрушениям и жертвам населения землетрясений [18].

Объяснение активизации геодинамической нестабильности Земли в период с августа по март (с соответствующим увеличением количества и масштабов катастроф) дается в информации уже упоминавшихся трех европейских служб времени: именно в этот период продолжительность суток увеличивается [13] на 0,0024 с. Для обычного восприятия эта величина представляется ничтожно малой, но в масштабах земного шара она оказывает существенное влияние на геодинамический режим движения Земли. Таким образом, можно с полным основанием говорить о ротационно-пульсационном режиме существования нашей планеты, тем более что первопричиной ротации является периодическое изменение радиуса Земли как вращающегося тела. Термин «ротационно-пульсационный режим» впервые предложил Г.Н. Каттерфельд [20], который, в свою очередь, выдвинул и свою версию неравномерности суточного вращения Земли, а именно, неравномерность разогрева планеты в процессе ее гравитационного уплотнения.

Увеличение длительности суток в период с августа по март влечет за собой приращение импульса силы тяготения между Землей и Солнцем, определяющей движение Земли по своей орбите. Согласно закону о сохранении количества движения, его приращение равно приращению импульса силы, вызывающей движение. Можно допустить и обратную трактовку: приращение импульса силы равно приращению количества движения:

$$
\Delta S=\Delta Q
$$

где $\Delta S$ - приращение импульса силы, равное

$$
\Delta S=F \Delta t,
$$

где $F$ - сила притяжения Земли к Солнцу; $\Delta t-$ приращение продолжительности суток; $\Delta Q-$ приращение количества движения:

$$
\Delta Q=m \Delta v,
$$

где $\Delta v$ - приращение скорости, которое равно $\Delta \nu=\omega \Delta R ; \omega$ - угловая скорость вращения; $\Delta R-$ приращение радиуса Земли или расширение толщины земной коры.

Таким образом, в период с августа одного года по март следующего года Земля увеличивается в своих размерах, что сопровождается расширением земной коры с активизацией вулканизма, ростом числа землетрясений, расширением тектонических разломов и увеличением числа и степени раскрытости трещин в блоках горных пород.

В другой период года (с марта по август) процесс идет в обратном направлении: радиус Земли сокращается из-за уменьшения импульса силы тяготения к Солнцу, земная кора сжимается с закрытием малых трещин и уменьшением раскрытости крупных, в том числе и разломов, снижается тек- тоническая активность, уменьшаются количество и масштабы землетрясений и проявлений вулканизма (рис. 2).

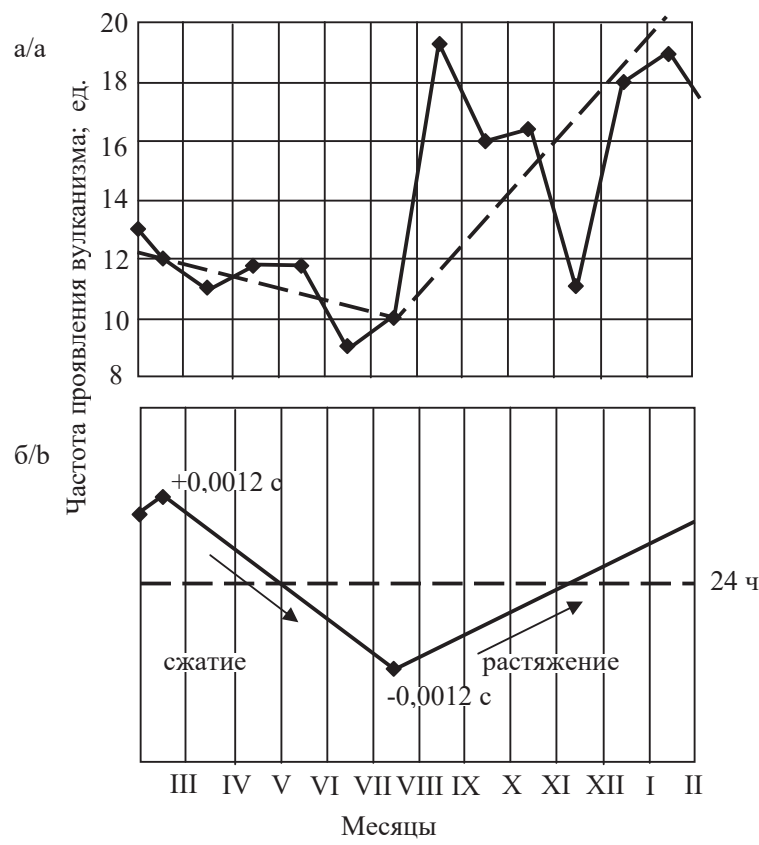

Pис. 2. Изменение интенсивности вулканизма (а) и длительно сти суток (б) по месяиам года: --- усредненная интен сивность; точки-статистические данные

Fig. 2. Changes in volcanism intensity (a) and day duration (b) by the months of the year: --- the average intensity; points statistics

Чтобы оценить степень влияния процессов расширения и сжатия земной коры, следует помнить, что горные породы имеют прочность на растяжение в 20-50 раз ниже прочности на сжатие. Поэтому период расширения земной коры в течение года наиболее опасен, так как именно на этот период приходится большинство как природных, так и техногенных катастроф с высокой степенью их повторяемости. Этим, например, можно объяснить возникновение с малым промежутком одна за другой двух крупных аварий на шахте «Ветка Глубокая» им. А.Ф. Засядько в Донбассе: прорыв аномальных количеств метана, взрыв его вместе с угольной мелочью, пожар, обрушение выработок с трагическими последствиями.

\section{Заключение}

Все шахты Центрального Донбасса, а упоминаемая шахта в особенности, отличаются повышенной загазованностью, увеличивающейся с глубиной горных работ. Шахта им. А.Ф. Засядько имеет глубину более 1200 м, что соответствует верхним горизонтам Прикарпатской нефтегазоносной провинции. При расширении литосферы в этом регионе, да и в соседних тоже, усиливается макро- и микротрещиноватость слагающих разрез этой провинции горных пород, в результате чего открываются дополнительные пути миграции углеводоро- 
дов, метана в том числе, масштабы которой, по мнению И.М. Губкина [19], могут характеризоваться гигантскими расстояниями, сравнимыми с расстоянием от Карпат до Центрального Донбасса.

Если бы геологическая служба шахты им. А.Ф. Засядько обращала более серьезное внимание на периодичность проявления аномальной газообильности в очистных забоях и подготовительных выработках, то можно было бы и применить специальные меры по предупреждению аварий или, по крайней мере, снижению масштаба их последствий: усиление вентиляции; сокращение добычи угля вплоть до временного прекращения деятельности шахты в опасный период с августа по март.

Таким образом, уровень геодинамической стабильности Земли, особенно в пределах земной коры, налагает особые требования:

\section{СПИСОК ЛИТЕРАТУРЫ}

1. Сагалович 0.И. Хроника глобальных катастроф. Бинарная геодинамика. - Санкт-Петербург: Недра, 2003. - 225 с.

2. Байда С.Е. Природные, техногенные и биолого-социальные катастрофы: закономерности возникновения, мониторинг и прогнозирование. - М.: Всероссийский научно-исследовательский институт по проблемам гражданской обороны и чрезвычайных ситуаций Министерства чрезвычайных ситуаций России, федеральный центр науки и высоких технологий, 2013. $194 \mathrm{c}$.

3. Хлебопрос Р.Г., Фет А.И. Природа и общество: модели катастроф. - Новосибирск: Сибирский хронограф, 1999. - 344 с.

4. Головнев А. Крупнейшие атомные аварии (экономика, управление, инновации). Сводка крупнейших атомных аварий с сентября 1944 г. по март 2011 г. // Экология и жизнь. 2011. - № 4. - C. 39-40.

5. Бондур В.Г., Крапивин В.Ф., Потапов И.И., Солдатов В.Ю. Природные катастрофы и окружающая среда // Проблемы окружающей среды и природных ресурсов. - 2012. - Вып. 1. C. $3-162$.

6. Аплонов С.В. Геодинамика. - СПб.: Изд-во Санкт-Петербургского государственного университета, 2001. - 360 с.

7. Хаин В.Е., Ломизе М.Г. Геотектоника с основами геодинамики. - М.: Изд-во Московского государственного университета, 1995. $-480 \mathrm{c}$.

8. Деменецкая Р.М. Кора и мантия Земли. - М.: Недра, 1985. $256 \mathrm{c.}$

9. Стовас М.В. Избранные труды. Ч. 1. - М.: Недра, 1975. - 156 с.

10. Веселовский В.А., Платэ А.Н. Вулканическая активность полуострова Камчатки // Проблемы окружающей среды и природных ресурсов. - 2010. - Вып. № 5. - С.104-107.

11. Тарасов В. Саяно-Шушенская авария: факты и гипотезы // Наука и жизнь. - 2013. - № 7. - С. 18-30.

12. География. Современная иллюстрированная энциклопедия / под ред. А.П. Горкина. - М.: Росмэн-Пресс, 2006. - 624 с.

13. Парийский Н.Н. Изменение длины суток и деформаций Земли // Астрономический журнал. - 1945. - Т. 22. - Вып. 2. C. 89-96.

14. Амбарцумян В.А. (Название статьи не афишируется) // Известия Академии Наук Армянской Советской Социалистической Республики. - 1958. - Т. 11. - № 9. - С. 91-109.

15. Гришанков Г.Е. Литосфера: структура, функционирование, эволюция. - Симферополь: Оригинал-М, 2008. - 448 с.

16. Милановский Е.Е. Пульсационная гипотеза геотектоники, ее становление и значение для понимания закономерностей Зе-
- к качеству организации деятельности отраслей промышленности, связанных с проникновением в недра Земли и масштабным строительством;

- учету возможности возникновения природных катастроф, обычно сопровождаемых техногенными авариями;

- объему профилактических мероприятий по полному предупреждению или снижению уровня последствий таких катастроф и аварий.

Предполагаемый значительный объем экономических затрат позволит парировать отрицательное воздействие природных факторов на объекты природы, обеспечить безаварийность работы предприятий и организаций, а также снизить социальные расходы в отношении пострадавших и уровень издержек на аварийно-восстановительные работы.

мли // Научное наследие М.А. Усова и его развитие. - Новосибирск: Наука, 1984. - С. 107-141.

17. Милановский Е.Е. Пульсация и расширение Земли - возможный ключ к пониманию её тектонического развития и вулканизма в фанерозое // Природа. -1978. - № 7. - С. 20-27.

18. Белоусов В.В., Шанцер Е.В. Геодинамические процессы и основные черты структуры земной коры // Большая Советская энциклопедия. Т. 9. - М.: Советская энциклопедия, 1972. C. $482-483$.

19. Одесский И.А., Декусар З.Б. Об одной из причин природных катастроф // Экология и развитие общества: Сборник материалов XIII Международной научно-практической конференции. - СПб.: МАНЭБ, 2008. - С. 48-56.

20. Unusual Rock Mechanics Challenges Encountered During Constructionofa Large Dam / C. Vibert, A. Azeb, S. Ianos, E. Mine // Rock Mechanics for Global Issues: $8^{\text {th }}$ Asian Rock Mechanics Symposium. - Japan, Sapporo: Japanese Committee for Rock Mechanics, October 2014. - P. 2085-2095.

21. Ware K., Westion J.F., Dickinson J.A. Investigation of a Canyon System off Cote D'Ivoire to Determine Present Day Risk of Slope Instability for a Field Development // SUT Conference Paper. UK, 2012. - P. 543-550.

22. Sharra L., Bozo L., Allkja S. Unstable rock masses in the highway Durres-Prishtina // Rock Engineering and Rock Mechanics: Structures in and on. - London: Taylor \& Francis Group, 2014. P. 1171-1774.

23. Zhang Yujie, Wang Yanqiu, Jaiswal Priyank. A Model for Propagation of Tensile Fractures in Heterogeneous Natural Media // SEG Conference Paper. - USA: New Orleans Annual Meeting, 2015. - P. 5174-5178. URL: http://dx.doi.org/10.1190/segam2015-5930036.1 (дата обращения 25.04.2019).

24. Hamed Berimani, Homayoon Khoshravan. Caspian Sea Southern Coasts Seismic Vulnerability // International offshore and Polar Engineering Conference. - USA, Hawaii, 19-24 June, 2011. P. $660-664$.

25. Delineation of Gravitational Instability Induced by Gas Charges into Oil Reservoirs Using Diffusion and Flory-Huggins-Zuo Equations / J.Y. Zuo, Sh. Pan, K. Wang et al. // SPE Conference Paper. - Australia, Perth, 25-27 October, 2016. - P. 546-559.

26. Geomechanics in Unconventional Reservoir: a New Approach to Drilling Integrating Advanced Acoustic Measurements and Formation Evaluation / C. Chatterjee, A. Reyes et al. // SPE Conference Paper. - Australia, Brisbane, 23-25 October, 2018. - P. 42-60.

27. Landscape Transformation Associated to the Development of Camisea Project and the Effectiveness of the Off Shore in Land Ap- 
proach / G. Leunda, G. Dias, E. Mendoza, N. Capello // SPE Conference Paper. - Argentina, Buenos Aires, 18-19 May, 2017. P. 58-67.

28. The Critical Role of Asphaltene Gradients and Data Integration in Reservoir Fluid Geodynamics Analysis / 0.C. Mullins, H. Dumont et al. // SPE Conference Paper. - USA, Texas, San Antonio, 9-11 October, 2017. - P. 543-563.

29. Chen G., Kawakami T., Zhang Y. Mechanism analysis of earthquake Induced Extreme Motions: Clarifying Extreme Accleration // Proc. of $51^{\text {st }}$ US Rock Mechanics. Geomechanics Symposium. - California, San Francisco: American Rock Mechanics Association, 25-28 June, 2017. - P. 426-432.

30. Azhari A., OzbayU. Evaluating the Effect of Earthquakeson 0pen Pit Mine Slopes // Proc. of $50^{\text {st }}$ Rock Mechanics. Geomechanics
Symposium. - Texas, Houston: American Rock Mechanics Association, 26-29 June, 2016. - P. 315-324.

31. Williams-Stroud S.C. Earth Stress and Seismic Hazard from the Size-Frequency Distribution of Seismic Events // Proc. of $51^{\text {st }}$ Rock Mechanics. Geomechanics Symposium. - California, San Francisco: American Rock Mechanics Association, 25-28 June, 2017. - P. 544-550.

32. Williams-Stroud S.C. A geological approach to seismicity b-values: Implications for hazard assessment // Proc. of SEG International Exposition and $87^{\text {th }}$ Annual Meeting. - USA, Texas, Houston, 2017. - P. 5381-5385.

Поступила 29.04.2019 2.

\section{Информация об авторах}

Борисов К.И., доктор технических наук, доцент, заведующий кафедрой бурения нефтяных и газовых скважин Сибирского федерального университета.

Горшков Л.К., заслуженный деятель науки Российской Федерации, доктор технических наук, профессор, вице-президент Международной академии наук экологии, безопасности человека и природы.

Софьин А.П., кандидат технических наук, доцент, доцент Международной академии наук экологии, безопасности человека и природы.

Федорова Л.А., кандидат технических наук, доцент, доцент Международной академии наук экологии, безопасности человека и природы. 
UDC 622.831

\title{
NATURAL-TECHNOLOGICAL DISASTERS AS MANIFESTATIONS OF GEODYNAMIC INSTABILITY OF THE EARTH'S CRUST
}

\author{
Konstantin I. Borisov' \\ kibor1956@gmail.com \\ Lev K. Gorshkov², \\ maneb@mail.ru \\ Alexey P. Sofin', \\ as-114@yandex.ru \\ Lyudmila A. Fedorova², \\ kingalya@mail.ru \\ ' Siberian Federal University, \\ 79/10, Svobodny avenue, Krasnoyarsk, 660041, Russia. \\ 2 International Academy of Sciences of ecology, human and nature safety, \\ 9, 26 line of Vasilievsky island, St. Petersburg, 199026, Russia.
}

The relevance. Geodynamic instability is the cause of many natural disasters: earthquakes, volcanic eruptions, landslides, tsunamis. Natural disasters can trigger man-made accidents (collapse of buildings and structures, explosions in mines, dam integrity violations, etc.) and, conversely, man-made processes can cause the emergence of new natural objects, for example, they are associated with the creation of artificial reservoirs. The widespread oil and gas production in the world can provoke movements in the earth's crust with tragic consequences. The features of conditions for activation of geodynamic instability determine the level of safety of personnel of technical facilities and the quality of operation of facilities, systems and units. The random nature of the processes in the earth's crust to a large extent forms the possibility of predicting man-made disasters and measures to parry the negative factors associated, including the safety of personnel and the population. Examples of natural and man-made disasters and the conditions of their occurrence as well as the recommendations for their prevention and prediction are given. Different points of view on activation of hemodynamic instability of the Earth, as well as the influence of seasonal periodicity of characteristic processes on it were compared. The level of significance of the earth motion parameters in the formation of the conditions of activation of geodynamic instability is substantiated. The relevance lies in the need for additional research in this area, which is partially filled by this article.

The aim of the research is to identify and propose an approach to analyze the catastrophic situation conditions.

Objects: geodynamic processes in the earth's crust and variants of combination of conditions for their occurrence.

Methods: review and analysis of existing scientific and technical information on the problem of geodynamic stability of the earth's crust and formulation of research tasks.

Results. The causes of emergency situations associated with geodynamic processes in the earth's crust are identified and justified.

\section{Key word:}

Geodynamic instability, crust, exogenous and endogenous processes, pulsation hypothesis,

natural and technogenic catastrophes, technogenic accidents, force impulse, period, I. Kepler's law, rotational-impulse regime.

\section{REFERENCES}

1. Sagalovich 0.I. Khronika globalnykh katastrof. Binarnaia geodinamika [Chronicle of global catastrophes. Binary geodynamics]. St-Petersburg, Nedra Publ., 2003. 225 p.

2. Baida S.E. Prirodnye, tekhnogennye i biologo-sotsialnye katastrofy: zakonomernosti vozniknoveniya, monitoring i prognozirovanie [Natural, technogenic and biological-social disasters: patterns of occurrence, monitoring and forecasting]. Moscow, VNII GOCHS (FC) Publ., 2013. 194 p.

3. Khlebopros R.G., Fet A.I. Priroda i obshchestvo: modeli katastrof [Nature and society: models of catastrophes]. Novosibirsk, Siberian chronograph Publ., 1999. 344 p.

4. Golovnev A. Major nuclear accidents (Economics, management, innovation). Summary of the largest nuclear accidents from September 1944 to March 2011. Ecology and life, 2011, no. 4, pp. 39-40. In Rus.

5. Bondur V.G., Krapivin V.F., Potapov I.I. Natural disasters and the environment. Problems of the environment and natural resources, 2012, Iss. 1, pp. 3-162. In Rus.
6. Aplonov S.V. Geodinamika [Geodynamics]. St-Petersburg, State university Publ., 2001. $360 \mathrm{p}$.

7. Khain V.E., Lomize M. G. Geotektonika s osnovami geodinamiki [Geotectonics with bases of geodynamics]. Moscow, Moscow state University Publ., 1995. 480 p.

8. Demenitskaya R.M. Kora i mantiya Zemli [Crust and mantle of the Earth]. Moscow, Nedra Publ., 1985. 256 p.

9. Stovas M.V. Izbrannye trudy [Selected works]. P. 1. Moscow, Nedra Publ., 1975. 156 p.

10. Veselovsky V.A. Vulkanicheskaya aktivnost poluostrova Kamchatki [Volcanic activity of the Kamchatka Peninsula]. Problems of environment and natural resources, 2010, Iss. 5, pp. 104-107.

11. Tarasov V. Sayano-Shushenskaya accident: facts and hypotheses. Science and life, 2013, no. 7, pp. 18-30. In Rus.

12. Geografiya. Sovremennaya illyustrirovannaya entsiklopediya [Geography. Modern illustrated encyclopedia]. Ed. by A.P. Gorkin. Moscow, Rosman-Press, 2006. 624 p.

13. Pariyskiy N.N. The change in the length of day and deformations of the Earth. Astronomy reports, 1945, vol. 22, Iss. 2, pp. 89-96. In Rus. 
14. Ambartsumyan V.A. (Nazvanie ne afishiruetsya) [No named published]. News of the Academy of Sciences of the Armenian Soviet Socialist Republic, 1958, vol. 11, no. 9, pp. 91-109.

15. Grishankov G.E. Litosfera: struktura, funktsionirovanie, evolyutsiya [Lithosphere: structure, functioning, evolution]. Simferopol, Original-M, 2008. 448 p.

16. Milanovsky E.E. Pulsatsionnaya gipoteza geotektoniki, ee stanovlenie i znachenie dliya ponimaniiya zakonomernostey Zeml [Pulsation hypothesis of geotectonics, its formation and importance for understanding the laws of the earth]. Nauchnoe nasledie M.A. Usova i ego razvitie [Scientific heritage of M.A. Usov and its development]. Novosibirsk, Nauka Publ., 1984. pp. 107-141.

17. Milanovsky E.E. Pulsation and expansion of the Earth is a possible key to understanding its tectonic development and volcanism in Phanerozoic. Nature, 1978, no. 7, pp. 20-27. In Rus.

18. Belousov V.V. Shantser E.V. Geodinamicheskie prottsessy i osnovnye cherty struktury zemnoy kory [Geodynamic processes and the main features of the earth crust structure]. Bolshaya sovet skaya entsiklopediya [The Great Soviet encyclopedia]. Moscow, Sovetskaya entsiklopediya Publ., 1972. Vol. 9. pp. 482-483.

19. Odesskii I.A. Ob odnoy iz prichin prirodnykh katastrof [The causes of natural disasters]. Ekologiya i razvitie obshchestva. Sbornik materialov XIII Mezhdunarodnoy nauchno-prakticheskoy konferentsii [Ecology and development of society: Proc of the XIII International scientific-practical conference]. St-Peterburg, MANEB Publ., 2008. pp. 48-56.

20. Vibert C., Azeb A., Ianos S., Mine E. Unusual Rock Mechanics Challenges Encountered During Construction of a Large Dam. $8^{t}$ Asian Rock Mechanics Symposium. Rock Mechanics for Global Issues. Japan, Sapporo, Japanese Committee for Rock Mechanics, October 2014, pp. 2085-2095.

21. Ware K., Westion J.F., Dickinson J.A. Investigation of a Canyon System of Cote D'Ivoire to Determine Present Day Risk of Slope Instability for a Field Development. SUT Conference Paper. UK, 2012. pp. 543-550.

22. Sharra L., Bozo L., Allkja S. Unstable rock masses in the highway Durres-Prishtina.Rock Engineering and Rock Mechanics: Structures in and on. London, Taylor \& Francis Group, 2014. pp. 1171-1774.

23. Zhang Yujie, Wang Yanqiu, Jaiswal Priyank. A Model for Propagation of Tensile Fractures in Heterogeneous Natural Media. SEG Conference Paper. USA, New Orleans Annual Meeting,
2015, pp. 5174-5178. Available at: http://dx.doi.org/10.1190/ segam2015-5930036.1 (accessed 25 April 2019).

24. Hamed Berimani, Homayoon Khoshravan. Caspian Sea Southern Coasts Seismic Vulnerability. International offshore and Polar Engineering Conference. USA, Hawaii, 19-24 June, 2011. pp. 660-664.

25. Zuo J.Y., Pan Sh., Wang K. Delineation of Gravitational Instability Induced by Gas Charges into Oil Reservoirs Using Diffusion and Flory-Huggins-Zuo Equations. SPE Conference Paper. Australia, Perth, 25-27 October, 2016. pp. 546-559.

26. Chatterjee C., Reyes A. Geomechanics in Unconventional Reservoir: a New Approach to Drilling Integrating Advanced Acoustic Measurements and Formation Evaluation. SPE Conference Paper. Australia, Brisbane, 23-25 October, 2018. pp. 42-60.

27. Leunda G., Dias G., Mendoza E., Capello N. Landscape Transformation Associated to the Development of Camisea Project and the Effectiveness of the Off Shore in Land Approach. SPE Conference Paper. Argentina, Buenos Aires, 18-19 May, 2017. pp. 58-67.

28. Mullins 0.C., Dumont H. The Critical Role of Asphaltene Gradients and Data Integration in Reservoir Fluid Geodynamics Analysis. SPE Conference Paper. USA, Texas, San Antonio, 9-11 October, 2017. pp. 543-563.

29. Chen G., Kawakami T., Zhang Y. Mechanism Analysis of Earthquake Induced Extreme Motions: Clarifying Extreme Acceleration. Proc. of 51' Rock Mechanics. Geomechanics Symposium. California, San Francisco, American Rock Mechanics Association, 25-28 June, 2017. pp. 426-432.

30. Azhari A., Ozbay U. Evaluating the Effect of Earthquakes on Open Pit Mine Slopes. Proc. of 50 Rock Mechanics. Geomechanics Symposium. Texas, Houston, American Rock Mechanics Association, 26-29 June, 2016. pp. 315-324.

31. Williams-Stroud S.C. Earth Stress and Seismic Hazard from the Size-Frequency Distribution of Seismic Events. Proc. of $51^{\text {st }}$ Rock Mechanics. Geomechanics Symposium. California, San Francisco, American Rock Mechanics Association, 25-28 June, 2017. pp. 544-550.

32. Williams-Stroud S.C. A geological approach to seismicity b-values: Implications for hazard assessment. Proc. of SEG International Exposition and $87^{\text {th }}$ Annual Meeting. USA, Texas, Houston, 2017. pp. 5381-5385.

\section{Information about the authors}

Konstantin I. Borisov, Dr. Sc., associate professor, head of department, Siberian Federal University.

Lev K. Gorshkov, Honoured Science Worker, Dr. Sc., professor, V.P., International Academy of Sciences of ecology, human and nature safety.

Alexey P. Sofin, Cand. Sc., associate professor, International Academy of Sciences of ecology, human and nature safety.

Lyudmila A. Fedorova, Cand. Sc., associate professor, International Academy of Sciences of ecology, human and nature safety. 